OPEN ACCESS

Edited by:

José Lozano,

University of Malaga, Spain

Reviewed by:

Gianluca Vadalà,

Campus Bio-Medico University, Italy

Laura S Stone,

University of Minnesota Twin Cities, United States

*Correspondence:

Zengwu Shao

szwpro@163.com

Xiangcheng Qing

353220817@qq.com

Yan Xiao

674174890@qq.com

Specialty section:

This article was submitted to

Signaling,

a section of the journal

Frontiers in Cell and Developmental

Biology

Received: 18 November 2021

Accepted: 27 December 2021

Published: 01 February 2022

Citation:

Lin $H$, Tian S, Peng $Y, W u L$, Xiao $Y$,

Qing $X$ and Shao $Z$ (2022) IGF

Signaling in Intervertebral Disc Health

and Disease.

Front. Cell Dev. Biol. 9:817099.

doi: $10.3389 /$ fcell.2021.817099

\section{IGF Signaling in Intervertebral Disc Health and Disease}

\author{
Hui Lin ${ }^{1}$, Shuo Tian ${ }^{1}$, Yizhong Peng ${ }^{1}$, Ling Wu ${ }^{1}$, Yan Xiao ${ }^{2 *}$, Xiangcheng Qing ${ }^{1 *}$ and \\ Zengwu Shao ${ }^{1 *}$
}

${ }^{1}$ Department of Orthopedics, Union Hospital, Tongji Medical College, Huazhong University of Science and Technology, Wuhan, China, ${ }^{2}$ Department of Radiology, Union Hospital, Tongji Medical College, Huazhong University of Science and Technology, Wuhan, China

Low back pain (LBP) is a common musculoskeletal symptom, which brings a lot of pain and economic loss to patients. One of the most common causes of LBP is intervertebral disc degeneration (IVDD). However, pathogenesis is still debated, and therapeutic options are limited. Insulin-like growth factor (IGF) signaling pathways play an important role in regulating different cell processes, including proliferation, differentiation, migration, or cell death, which are critical to the homeostasis of tissues and organs. The IGF signaling is crucial in the occurrence and progression of IVDD. The activation of IGF signaling retards IVDD by increasing cell proliferation, promoting extracellular matrix (ECM) synthesis, inhibiting ECM decomposition, and preventing apoptosis and senescence of disc cells. However, abnormal activation of IGF signaling may promote the process of IVDD. IGF signaling is currently considered to have a promising treatment prospect for IVDD. An in-depth understanding of the role of IGF signaling in IVDD may help find a novel approach for IVDD treatment.

Keywords: insulin-like growth factor, intervertebral disc, nucleus pulposus, degeneration, low back pain

\section{INTRODUCTION}

Intervertebral disc degeneration (IVDD) is a paramount contributor to low back pain and is a leading cause of disability that reduces the quality of life and causes economic loss (Feng et al., 2017; Choi et al., 2019). The structural failure of degenerative discs is marked by disc height collapse, annulus fibrosus (AF) fissures, loss of proteoglycan (PGs) and water in the nucleus pulposus (NP), and cartilage endplate (CEP) calcification (Lappalainen et al., 2014; Silagi et al., 2018; Kim et al., 2021). The prevalence of IVDD is continuously increasing because of the rise in population age (DePalma et al., 2011; Choi et al., 2019). However, the current therapy approach of IVDD treatment is to relieve pain using therapies such as physical therapy, drugs, or interbody fusion surgery (Vadala et al., 2015; Chen et al., 2017). There is still no curative therapy today.

The insulin-like growth factor (IGF) signaling pathways play an important role in regulating various cell activities, including proliferation, differentiation, migration, or cell death, which are critical to the homeostasis of tissues and organs (Duan and Xu, 2005; Rafacho et al., 2009; Lunn et al., 2015). Several investigations have indicated that IGF signaling is critical in the progression of IVDD. Studies have reported that the expressions of IGF are significantly abnormal in degenerative IVD tissues and cells, and it is involved in multiple pathological processes of disc degeneration by participating in cell proliferation, programmed death, degeneration and synthesis of ECM (Tao et al., 2015; Chen et al., 2020; Zhao et al., 2020). IGF signaling is considered to be a promising approach for treatment strategies of IVDD. Here, we review the literature describing how IGF signaling is involved in IVDD pathophysiology and describe recent progression regarding its administration as a promising biological therapeutic approach for disc degeneration. 


\section{IGF SIGNALING}

The IGF axis is composed of ligands such as insulin, insulin-like growth factors 1 and 2 (IGF1, IGF2), receptors (IGF-1R, IGF-2R), IGF binding proteins (IGFBPs) one to seven, and IGFBP protease (Martel-Pelletier et al., 1998; Wang et al., 2014; Hua et al., 2020; Ianza et al., 2021). IGF ligands bind its receptors and binding proteins with high affinity (Huang et al., 2011a; Okamoto et al., 2013). The function of IGFBPs is to bind to IGF, extend the circulating half-life, and prevent the activation of IGF receptors (Patel and Majumdar, 2009; Kobayashi-Hattori et al., 2011). IGFBP protease cleaves IGFBP into fragments with a lower affinity for IGF ligands, thereby improving the bioavailability of free IGF (Peters et al., 2003; Ianza et al., 2021). Three main proteases can cleave IGFBP, including serine proteases, cathepsins, and matrix metalloproteinases (MMPs) (Grimberg and Cohen, 2000; Garcia-Touchard et al., 2005; Chao et al., 2021). The IGF in the intervertebral disc may come from two sources: 1. Circulating IGF1 secreted by the liver; The lack of IGF1 content in plasma can reduce the formation of the IGF1R binding complex in the intervertebral discs by 10-20\% (Elmasry et al., 2016). 2. Autocrine/paracrine IGF in the intervertebral disc tissue (Osada et al., 1996; Elmasry et al., 2016). Osada revealed that IGF1 mRNA was expressed in bovine nucleus pulposus cells and annulus fibrosus cells by in situ hybridization histochemistry detection. The staining of IGF1R was also positive in the disc cells by the avidin-biotin peroxidase complex method (Osada et al., 1996). Theoretically, with the progression of cartilage degeneration, the cartilage endplate will be calcified, resulting in the deterioration of the nutrition supply to the discs. Such pathological changes will impair the reach of circulating IGF to the intervertebral disc tissue (Urban et al., 2004; Wong et al., 2019). Therefore, the autocrine/paracrine mechanism of IGF in adult nucleus pulposus may be an important source of IGF in degenerative nucleus pulposus. The effects of IGF1 and IGF2 via autocrine/paracrine are mostly mediated by the IGF1 receptors (Kashyap et al., 2020). IGF1R is a heterotetrametric receptor ( $\alpha 2 \beta 2$ ) composed of two $\alpha$ and two $\beta$ subunits which require a series of post-translational modifications, such as glycosylation, disulfide linkage, and proteolytic cleavage, to reach their mature form (Gan et al., 2014; Singh et al., 2014; Kashyap et al., 2020). When the ligand binds to the corresponding receptor, it is activated by autophosphorylation of tyrosine kinases to stimulate IGF signaling pathways (Janssen, 2020; Jozefiak et al., 2021; Lero and Shaw, 2021). The autophosphorylation of tyrosine kinases recruited and activated insulin-receptor substrate 1 (IRS-1) and phosphatidiyl inositol 3 kinase (PI3K), which resulted in the conversion of phosphatidylinositol-3,4,5trisphosphate 2 (PIP2) to PIP3. The conversion brings PI3-kinase dependent kinase-2 (PDK2) and AKT Serine/Threonine Kinase (Akt) to the membrane and the phosphorylation of Akt activates a number of substrates to regulate protein synthesis, cell proliferation, apoptosis and other cellular activities (Bikle et al., 2015; Yoshida and Delafontaine, 2020; Moonesi et al., 2021). IGF1 can also activate the Grb2 adaptor protein and inducts the activation of Ras $G$ protein to initiate the mitogen-activated kinase (MAPK) pathway, which involves
Ras, Raf, MEK and ERK signaling molecules (Clemmons, 2006; Kasprzak, 2021).

IGF1 and its binding protein and receptor system play an important role in the development and degeneration of the intervertebral discs. IGF1 has been shown to affect early dorsal (spine) development, which can promote chondrocyte differentiation and embryonic bone development (Wang et al., 2006). In response to proinflammatory cytokine exposure, Pregnancy-associated plasma protein-A (PAPP-A), a metalloproteinase, cleaves IGFBP in the ECM, making IGF1 available to nearby cells (Gruber et al., 2013; Kritschil et al., 2020). IGF1 is associated with the cell surface receptor tyrosine kinase IGF1R to implement its functions. The binding of the ligand and receptor facilitates the recruitment and phosphorylation of the docking proteins insulin receptor substrates (IRS-1/2), eventually, a series of signaling pathways are triggered (Osher and Macaulay, 2019). Chothe reported that IGF1 upregulated the expressions of the sodium-dependent vitamin C transporter 2 (SVCT2), which facilitate cellular uptake of ascorbic acid from the ECM to maintain the collagen synthesis (Chothe et al., 2013). Zhao et al. unveiled that the activation of the IGF1/PI3K/CREB/CA12 signaling pathway attenuated IVDD by maintaining anabolism and preventing disc cell apoptosis (Zhao et al., 2020). Furthermore, several studies have demonstrated that IGF signaling activation slows IVDD by increasing ECM synthesis, cell proliferation, and inhibiting inflammatory responses, ECM degradation, and cell apoptosis, which are primarily regulated by the PI3K/Akt and MEK/ERK pathways (Pratsinis and Kletsas, 2007; Mavrogonatou and Kletsas, 2010; Pratsinis et al., 2012; Wei et al., 2013; Liu et al., 2015; Tao et al., 2015; Xu et al., 2019; Tian et al., 2020). These evidences indicate that the IGF signaling and its components may be potential new therapeutic targets for this disease (Figure 1).

\section{THE EXPRESSION OF IGF SIGNALING IN THE INTERVERTEBRAL DISCS}

Several studies focused on the expression of IGF signaling in the intervertebral discs, and the results showed that it was closely related to IVDD. Osada et al. shown that the expression levels of IGF1 and IGF1R mRNA in the nucleus pulposus of fetal bovine intervertebral discs were higher than those of the adult discs (Osada et al., 1996). However, Murakami found that the mRNA levels of IGF1 in the anulus fibrosus tissue from 3 years old rabbits were 2.0 times higher than in 6 months old rabbits, while in the nucleus pulposus tissue of the old rabbits were only 0.6 times than that in the young rabbits (Murakami et al., 2006). Okuda's semi-quantitative reverse transcriptionpolymerase chain reaction research also revealed no evidence of an age-related decrease in IGF1 expression. In terms of IGF1R, there was a significant decrease in 120-week-old cells. IGFBP- 1 is expressed more strongly in 40 -weeks cells than that in 8-weeks cells (Okuda et al., 2001). There is also still no consensus in the literature about the changes of IGF signaling pathways expression in human IVD tissues. Liu et al. reported that the activation of IGF1R was significantly decreased in 


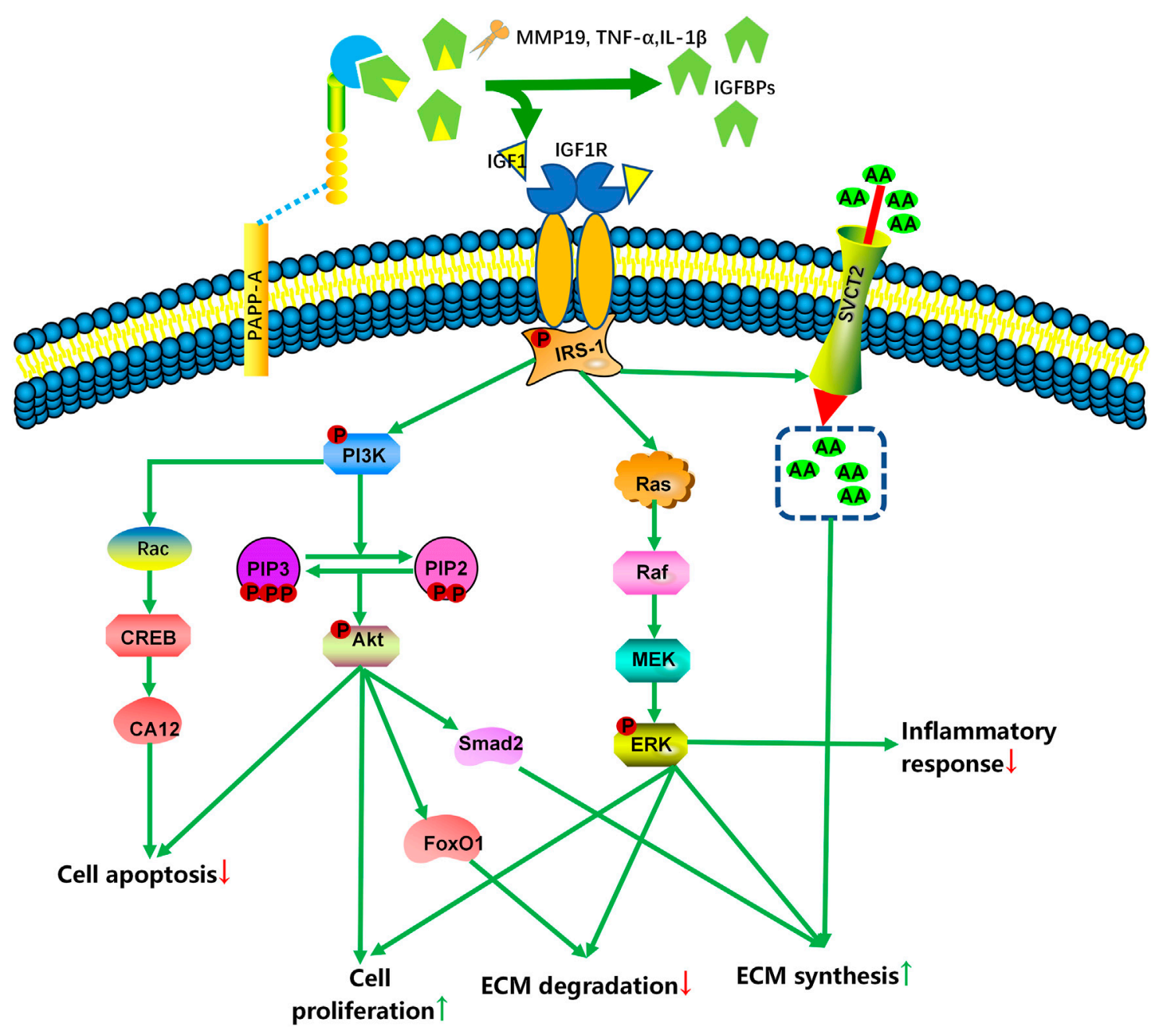

FIGURE 1 | Simplified scheme of IGF signaling in the intervertebral disc. With the participation of MMPs, TNF $\alpha$, or IL-1 $\beta$, PAPP-A cleaves IGFBP in the extracellular matrix, increasing the amount of bioavailable IGF1 and IGF2. To exert their effects, IGF bind to specific cell surface receptors (IGF1R and IGF2R). IGF1R activation activates various molecular signaling pathways, including the PI3K-Akt and RAS-extracellular signal-regulated kinase (ERK) pathways, to regulate IVD cell death and ECM content. MMP: matrix metalloproteinases; PAPP-A: pregnancy-associated plasma protein-A; IRS-1: insulin-receptor substrate 1; AA: ascorbic acid; SVCT2: sodium-dependent vitamin C transporter 2; PI3K: phosphatidiyl inositol 3 kinase; PIP: phosphatidylinositol-3,4,5-trisphosphate; FoxO1: forkhead box O1; CREB: CAMP-responsive element-binding protein; CA12: carbonic anhydrase 12; MEK: mitogen-activated protein kinase/extracellular signal-regulated kinase; ERK: extracellular signal-regulated kinase.

degenerated discs (Liu et al., 2015). Chen et al. used ELISA to analyze the levels of IGF1 and IGF1R expression in intervertebral discs with different degrees of degeneration classified according to magnetic resonance imaging and found that IGF1 and IGF1R content was decreased in higher degenerated NP tissues (Chen et al., 2020). However, Le Maitre et al., on the other hand, found that the expression of IGF1R showed no statistically significant differences between non-degenerate and degenerate biopsies (Le Maitre et al., 2005). Tsarouhas et al. also confirmed that the transcriptional levels of the IGF did not differ between the control and herniated groups (Tsarouhas et al., 2017). Interestingly, Specchia et al. discovered that the expression of IGF1 was stronger in herniated discs than in controls (Specchia et al., 2002). Research on the changes in the expression of IGF signaling pathways during the IVDD process is still in its infancy (Table 1). The variation in its expression may be associated with species and different stimulated conditions. One further point to note is that additional measures are needed to detect more IGF signalrelated molecules.

\section{IGF SIGNALING INHIBITS ECM DEGRADATION AND ENHANCES ECM SYNTHESIS}

IVD is a complicated joint structure made up of three major components. The IVD's center, NP, is gelatinous and resilient (Chung et al., 2003; Chou et al., 2016). The AF circumferentially 
TABLE 1 | The changes in the expression of IGF signaling in the IVDs of different species (NS, not significant).

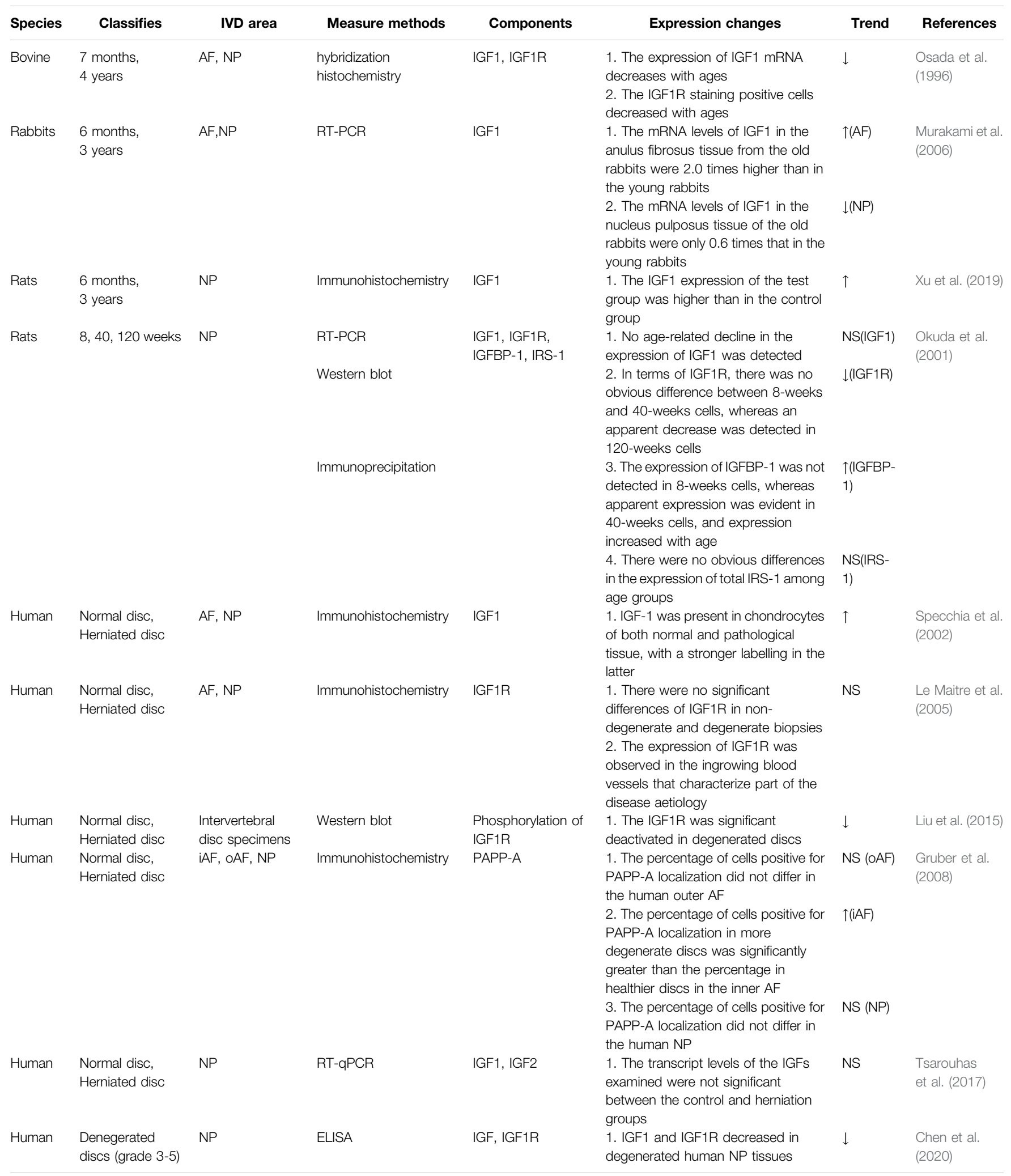


encapsulates the NP while the CEPs are located above and below the NP and AF (Hamilton et al., 2006; Merceron et al., 2014; Kim et al., 2021). The ECM of the NP is composed of collagen, especially type II, non-collagenous proteins, elastin, and proteoglycans (Loreto et al., 2011; Ghannam et al., 2017; Oichi et al., 2020). NP cells are responsible for maintaining the homeostasis and balance of ECM, thereby maintaining the integrity of disc structure and function (Wang et al., 2015b; Zhang et al., 2019). Aggrecan is the most abundant extracellular matrix in nucleus pulposus, which can account for $50 \%$ of the dry weight of nucleus pulposus (Le Maitre et al., 2007; Chen et al., 2013; Wang et al., 2015a). Aggrecan can absorb nutrients and water from the periphery through the creation of an osmotic gradient, thus maintaining the hydrophilic nature of NP (Bergknut et al., 2013; Wang et al., 2015a). The turnover of aggrecan in the intervertebral disc is an early sign of IVDD (Sivan et al., 2014). Type II collagen forms a fibrous framework to trap proteoglycans. It has tensile strength and is crucial in the biomechanical function of IVD (Li et al., 2013). In healthy intervertebral discs, due to the complex regulation of growth factors and catabolic factors, the rate of synthesis and decomposition of the extracellular matrix is balanced (Wang et al., 2020). Increased proteolytic degradation of aggregated polysaccharides and a rise in non-aggregated proteoglycans are early degenerative modifications in intervertebral discs (Kim et al., 2021). IVDD occurs when ECM catabolism exceeds anabolism (Guilak et al., 2018). Matrix metalloproteinases (MMPs) and disintegrins with thrombospondin motifs and metalloproteinases (ADAMTs) are important enzymes that cause the loss of the extracellular matrix (Zhang et al., 2021). A variety of ADAMTS and MMPs are up-regulated in degenerative IVD, and they are closely related to the destruction of the ECM and the progression of IVDD (Pockert et al., 2009; Tsarouhas et al., 2011; Huang et al., 2019).

Several studies have shown that IGF1 can promote the synthesis of ECM (Osada et al., 1996; Gruber et al., 2004; Moon et al., 2008; Kim et al., 2010; Hayes and Ralphs, 2011; Huang et al., 2011b; Illien-Junger et al., 2012; Chothe et al., 2013; Liu et al., 2014; Tao et al., 2015; Chen et al., 2020; Zhao et al., 2020). It also prevents ECM degradation by inhibiting MMPs, which increases the amount of matrix in the intervertebral disc and delays the progression of IVDD. MMP13 is an important enzyme in the degradation of ECM components such as collagen and proteoglycans (Zhang et al., 2009). In animals with IGFIR gene knockout, type II collagen and aggrecan gradually decreased, but the expression of MMP13 mRNA increased in a timedependent manner (Li et al., 2013). IGF1 treatment significanlty reduced MMP3 expression levels and increased ECM levels in mice degenerated discs conducted by leptin receptor knockout ( $\mathrm{Li}$ et al., 2020). In addition, in vitro studies had found that IGF1 increased the synthesis of proteoglycans and inhibited the production of MMP2 (Pattison et al., 2001). IGF1 can not only inhibit catabolism but also promote anabolism (Osada et al., 1996; Okuda et al., 2001; Pattison et al., 2001; Zhang et al., 2013; Kritschil et al., 2020; Li et al., 2020). IGF1 induces nucleus pulposus mesenchymal stem cells to synthesize ECM by up-regulating the expression of chondrogenic genes
COL2, ACAN and SOX-9 via the ERK/MAPK signaling pathway (Tao et al., 2015). IGF1 also regulates ECM anabolism by stimulating the production of proteoglycans in ECM (Travascio et al., 2014). Okuda et al. found that the synthesis of proteoglycans in rat nucleus pulposus cells at 8 weeks increased by 4 times compared with the control group. However, in 120weeks cells supplemented with long R3 IGF1, no significant upregulation of proteoglycan synthesis was detected. At the same time, the rise in IGFBP-1 in the early stages of aging contributes to the age-related decline in IGF1-dependent proteoglycan production (Okuda et al., 2001). Thus, the therapeutic effects of IGF1 in the increase of ECM are associated with the time of intervention. Simultaneously, we should attach importance to the role of IGF1R and IGFBPs in the regulation of IVDD. In addition, the specific molecular mechanisms of IGF signaling pathways in promoting the synthesis of ECM remain unclear (Figure 2).

\section{IGF SIGNALING PROMOTES CELL PROLIFERATION AND PREVENTS CELL DEATH}

The underlying mechanism of IVDD is disc cell death and loss. Studies have shown that IGF1 can relieve the inhibition of intervertebral disc cells proliferation by the adverse microenvironment (Zhang et al., 2006; Pratsinis and Kletsas, 2007; Mavrogonatou and Kletsas, 2010; Pratsinis et al., 2012;

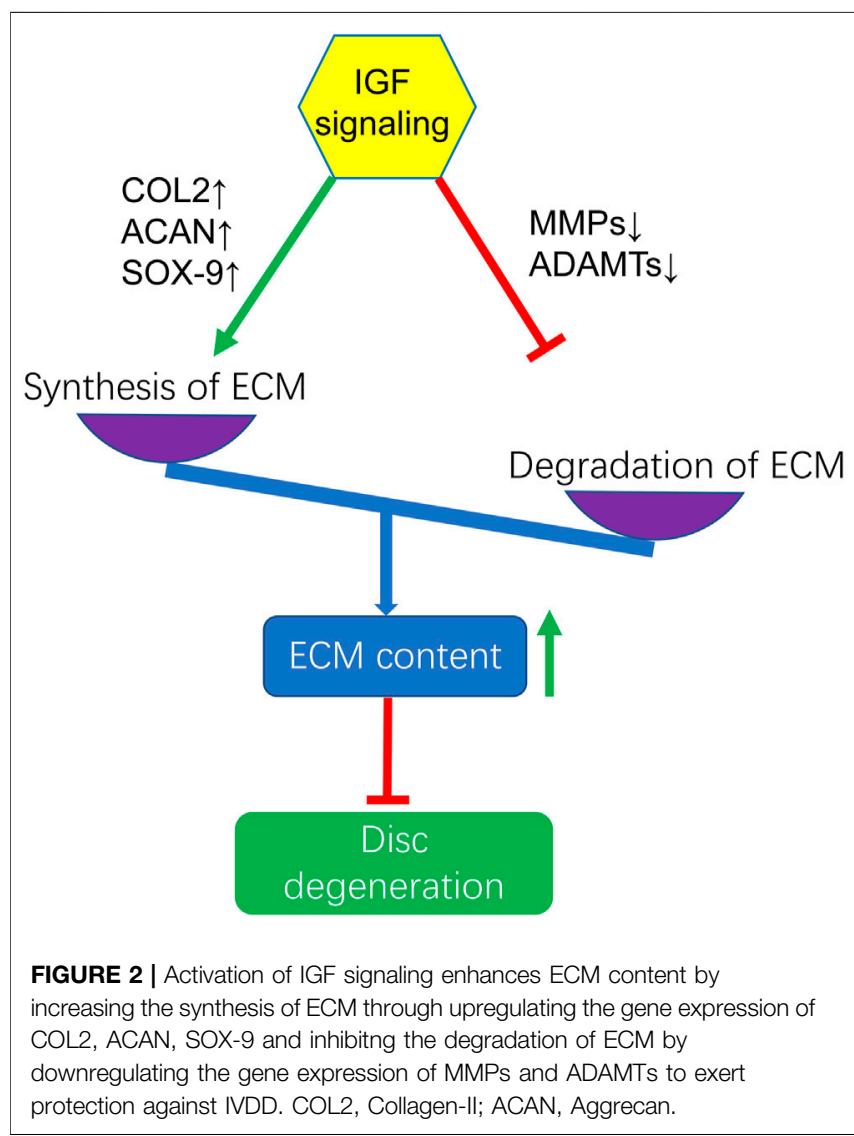


Tao et al., 2015; Akyuva et al., 2019; Chen et al., 2020; Kritschil et al., 2020). Pratsinis and Kletsas found that IGF1 increases IVD cell proliferation via the ERK and Akt signaling pathways (Pratsinis and Kletsas, 2007). Eleni et al. also reported that IGF1 stimulated DNA synthesis in NP cells under different osmotic conditions via the ERK and Akt signaling pathways (Mavrogonatou and Kletsas, 2010). Similarly, in 10\% fetal bovine serum, IGF1 at a concentration of $100 \mu \mathrm{g} / \mathrm{L}$ significantly increased cell proliferation (Zhang et al., 2006). This evidence indicates that IGF plays a positive regulatory role in promoting cell proliferation. However, the hyperproliferation of disc cells leads to a rise in nutrition consumption and demand, which has been implicated in IVDD (Guo et al., 2019). Therefore, the pro-proliferative effects of IGF are not necessarily to retards the process of IVDD. More research is required to explore the effects of IGF signaling on the degeneration of intervertebral discs in regulating cell proliferation in different periods.

As to programmed cell death, growing evidence indicates that IGF could retard cell apoptosis to delay IVDD (Gruber et al., 2000; Price et al., 2007; Liang et al., 2012; Zhang et al., 2013; Kuo et al., 2014; Li et al., 2020; Zhao et al., 2020). A study showed that the administration of IGF1 significantly reduced IL- $1 \beta$-induced apoptosis of NP cells (Zhang et al., 2013). Type II diabetes mellitus (T2DM) induced by leptin receptor knockout in mice led to IVDD by promoting disc cell apoptosis. IGF1 treatment partially reversed this situation (Li et al., 2020). Gruber proved that after exposure to

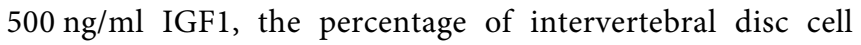
apoptosis was significantly reduced (Gruber et al., 2000). NP cells treated with an adenoviral vector expressing hIGF1 showed a decreased rate of apoptosis confirmed by the TUNEL test and FCM conducted by TNFa (Zhang et al., 2014). In addition, IGF1 can also inhibit cellular senescence caused by $\mathrm{H}_{2} \mathrm{O}_{2}$ (Gruber et al., 2008). In summary, these results indicate that IGF1 delays IVDD by inhibiting cell apoptosis. It is worth noting that although much published literature has confirmed that IGF1 can inhibit the apoptosis of disc cells caused by various unfavorable stimulation, there is still a lack of research on its specific signaling pathways. In addition, studies have confirmed that the degenerated intervertebral disc cells are mainly necrotic-like changes (Buckwalter, 1995). However, the effects of IGF on the programmed necrosis of NP cells have not been reported yet.

\section{ABNORMAL ACTIVATION OF IGF SIGNALING AGGRAVATES IVDD}

IGF signaling is involved in various diseases and is considered to have pleiotropic effects (Dixit et al., 2021). It has recently been reported that the over-activation of IGF signaling may contribute to the progress of IVDD. In the case of pathological nutritional insufficiency, exogenous injection of IGF1 is only beneficial to well-nourished areas in IVD, while in undernourished areas will increase cell mortality (Travascio et al., 2014). In addition, IGF1 promotes cell proliferation by increasing the production of PG and promoting cell metabolism, thereby increasing the nutritional requirements of the intervertebral discs (Pratsinis and Kletsas, 2007; Huang et al., 2012). This may further promote intervertebral disc degeneration because insufficient nutritional supply is considered to be the main cause of IVDD (Travascio et al., 2014). The injection of IGF in human IVD may induce unnecessary vascular ingrowth and accelerate the process of IVDD (Li et al., 2013). With an advancing grade of disc degeneration, enhancement of angiogenesis is usually accompanied by nerve ingrowth, producing painful discs (Le Maitre et al., 2005). The angiogenic potential of IGF may avail the ingrowth of blood vessels and bring painful discs (Le Maitre et al., 2005). Takayama et al. revealed that IGF1 knockdown resulted in a relief of mechanical allodynia in the dorsal root ganglion cells of a rat model of disc herniation (Takayama et al., 2011). Koerner collected intervertebral discs from patients who had undergone lumbar interbody fusion surgery for back pain and determined the expression levels of IGF1. The results indicated that IGF1 significantly increased in the posterior AF versus the anterior AF. Nonetheless, there were no differences in the anterior AF compared with posterior AF in the scoliosis group. The overexpression of growth factors may predispose the posterior AF to disc degeneration, compromise the structural properties of the discs and is associated with facet arthritis and discogenic pain (Koerner et al., 2014). In addition, the ultimate therapeutic effect of IGF1 varies as the concentration change. In $10 \%$ fetal bovine serum, IGF1 at a concentration of $100 \mu \mathrm{g} / \mathrm{L}$ significantly increased cell proliferation and showed a dose-dependent effect. However, the viability of NP cells declined as the concentration increased (Zhang et al., 2006). The activation of IGF1 leads to increased expression of IL-1 and IL-2 via the PI3K/Akt signaling pathway in herniated lumbar discs (Xu et al., 2019). These results indicate that the abnormal activation of IGF signaling pathways may accelerate the process of IVDD (Table 2).

\section{THERAPEUTIC EFFECTS OF IGF SIGNALING IN IVDD}

Both in vitro and in vivo studies have exhibited that IGF signaling may be a potential therapeutic target for the treatment of IVDD (Gruber et al., 2000; Gruber et al., 2001; Gruber et al., 2004; Moon et al., 2008; Mavrogonatou and Kletsas, 2010; Zhang et al., 2013; Akyuva et al., 2019; Zhao et al., 2020). The application of IGF for treating IVDD is mainly achieved through two different approaches: IGF injection into degenerative intervertebral discs and mesenchymal stem cell (MSC) transplantation (Feng et al., 2015). The results of these studies demonstrated promising effects (Feng et al., 2015). The administration of IGF may be helpful to retard disc degeneration by increasing cell proliferation, stimulating matrix synthesis, and inhibiting programmed cell death. For example, IGF injection into the intervertebral discs can effectively inhibit cell apoptosis and matrix degradation in degenerated discs in leptin receptor-deficient knockout mice model (Li et al., 2020). The addition of IGF1 to the culture of intervertebral disc cells has been shown to prevent the senescence of annulus fibrosus (AF) cells and promote the synthesis of 
TABLE 2 | Abnormal activation of IGF signaling aggravates IVDD.

\begin{tabular}{|c|c|c|}
\hline Author & Conclusion & References \\
\hline Travascio et al & $\begin{array}{l}\text { Exogenous injection of IGF1 is only beneficial to well-nourished areas in IVD, while in undernourished areas will increase cell } \\
\text { mortality }\end{array}$ & Travascio et al. (2014) \\
\hline Li et al & The injection of IGF in human IVD may induce unnecessary vascular ingrowth and accelerate the process of IVDD. & Li et al. (2013) \\
\hline Le Maitre et al & The angiogenic potential of IGF may avail the ingrowth of blood vessels and bring painful discs & Le Maitre et al. (2005) \\
\hline Takayama et al & IGF1 knockdown resulted in a relief of mechanical allodynia in the dorsal root ganglion cells of a rat model of disc herniation & Takayama et al. (2011) \\
\hline Koerner et al & High expression of IGF1 may be related to the pain experienced in IVDD. & Koerner et al. (2014) \\
\hline Zhang et al & $\begin{array}{l}\text { IGF1 at a concentration of } 100 \mu \mathrm{g} / \mathrm{L} \text { significantly increased cell proliferation but the viability of NP cells declined as the } \\
\text { concentration increased }\end{array}$ & Zhang et al. (2006) \\
\hline Xu et al & $\begin{array}{l}\text { The activation of IGF1 lead to increased expression of IL-1 and IL-2 via the PI3K/Akt signaling pathway in herniated lumbar } \\
\text { discs }\end{array}$ & Xu et al. (2019) \\
\hline
\end{tabular}

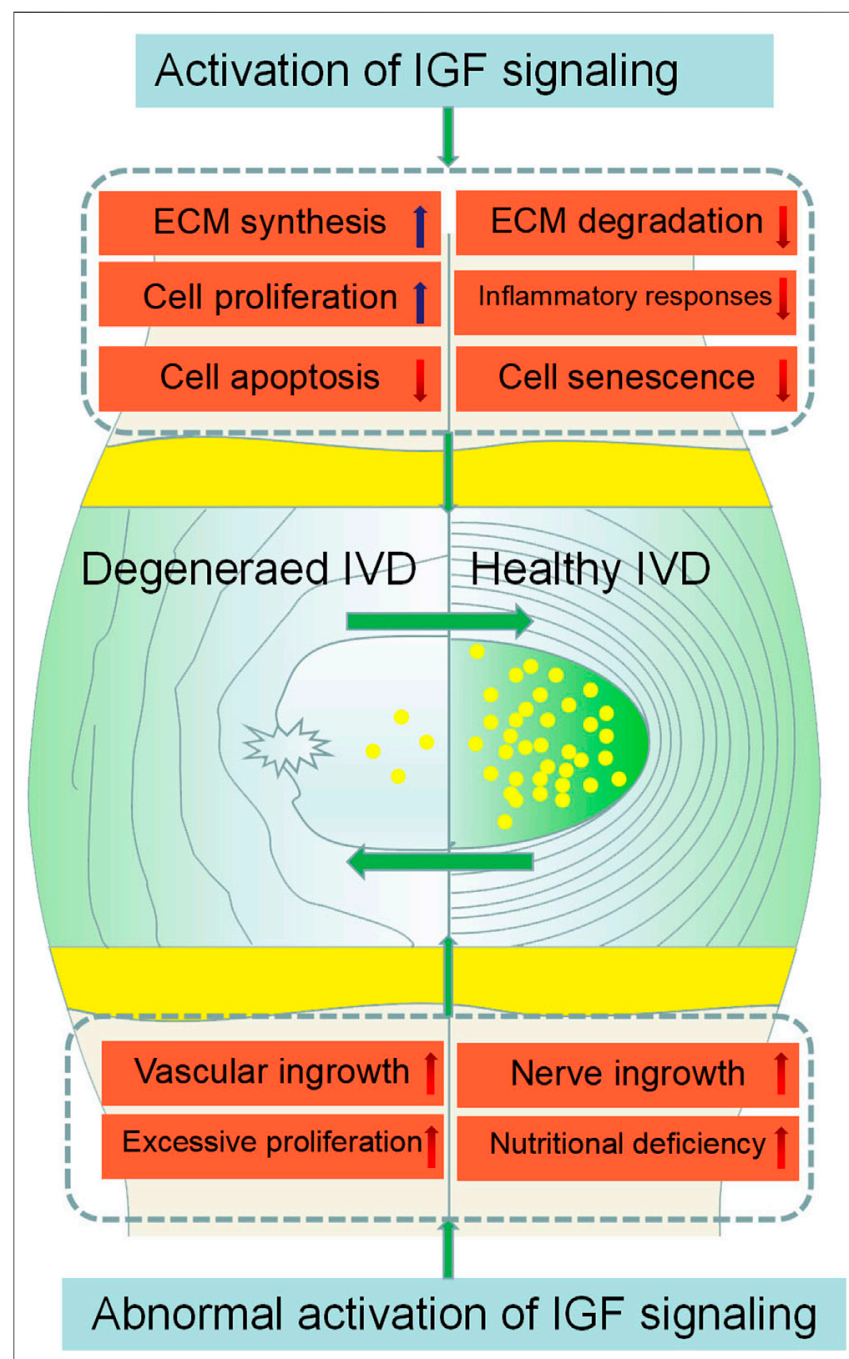

FIGURE 3 | Effects of IGF signaling on IVDD initiation and progression. IGF signaling activation inhibits IVDD by promoting ECM synthesis, cell proliferation, and inhibiting inflammatory responses, ECM degradation, and cell apoptosis. However, the abnormal activation of IGF signaling can accelerate the degeneration of IVD by stimulating excessive cell proliferation, increasing vascular and nerve growth, aggravating nutritional deficiency. proteoglycan in NP cells (Gruber et al., 2008). IGF1 treatment is considered to be a strategy to inhibit IVD degeneration in under T2DM conditions (Mahmoud et al., 2020). In recent years, tissue engineering and gene therapy technologies can provide sustained release of growth factors (Zhang et al., 2006). For example, studies have shown that injection of Ad/CMV-hIGF1 vector as gene therapy has more beneficial effects on rabbit IVDD cells than an injection of hIGF1 alone (Zhang et al., 2014). However, human IVDD is a multifactorial pathological process. The results obtained from in vitro and animals experements do not necessarily apply to humanity. Further research is needed to explore the exact role of IGF signaling in the treatment of IVDD using human disc cells.

In recent years, the application of stem cells combined with IGF has provided new ideas for IVDD treatment strategies. Studies have confirmed that IGF1 helps MSC to differentiate into NP-like phenotypes (Ehlicke et al., 2010; Illien-Junger et al., 2012; Chon et al., 2013; Liu et al., 2014; Tao et al., 2015; Kennon et al., 2018; Tian et al., 2020). These NP-like cells could be transplanted into degenerative discs to increase the number of functional cells in IVD or enhance the function of endogenous intervertebral disc cells (Shim et al., 2016). Under conditions of hypoxia and nutrient deficiency, adding IGF1 to hNP-MSCs can improve cell proliferation and prevent the decline of matrix gene expression, and inhibit cell apoptosis (Tian et al., 2020). The homing of bone marrow mesenchymal stem cells transduced with IGF1 can accelerate the synthesis of proteoglycan in degenerated intervertebral discs (Illien-Junger et al., 2012).

Although many studies have confirmed the promising results of the application of IGF in the treatment of IVDD, there are still challenges that limit its clinical application. The effects of IGF on cell proliferation, death, and matrix synthesis in intervertebral discs are complicated. The specific role of IGF signaling on intervertebral disc degeneration may be related to the dose and the time of application. Inappropriate use of IGF signaling may aggravate IVDD and contribute to the exacerbations of LBP. In the case of pathological nutritional insufficiency, exogenous injection of IGF1 is only beneficial to well-nourished areas in IVD, while in undernourished areas will increase cell mortality (Travascio et al., 
2014). The overexpression of IGF1 in posterior AF positively correlates with the pain experience among patients with IVDD (Koerner et al., 2014). Thus the IGF1 injection to this area may worsen the pain. In addition, PAPP-A showed a complex regulation of IVDD during aging. Deactivation of PAPP-A retarded disc cellular senescence and matrix catabolism but also inhibited matrix anabolism (Kritschil et al., 2020). A comprehensive understanding of IGF signal transduction and the related regulatory factors will contribute to developing better therapies for the treatment of IVDD. However, most patients may have severe intervertebral disc degeneration at the time of diagnosis, whereas IGF may have a better therapeutic effect in the early stage of degeneration. Although IGF may stimulate the endogenous repair mechanism, it may cause further disc damage due to the operation. The half-life of IGF ranges from $10 \mathrm{~s}$ to $2 \mathrm{~min}$. This limits its biological effects in vivo and restricts its applicability (Akyuva et al., 2019). There are several small molecules that have been developed to target the IGF signaling for the treatment of different diseases. A 14-residue peptidomimetic of IGF1, bp-1-101, which was able to block the IGF/IGFBP interactions, has been proposed as a therapeutic agent for stroke treatment (Rosenzweig, 2004). Natural metabolites of IGF1, glycine-prolineglutamate, cyclic glycine-proline as well as the structural analogues glycine-2-methyl-proline-glutamate and cyclo-L-glycyl-L-2allylproline exhibited valid neuroprotection (Guan et al., 2015). Small molecules targeting the IGF signaling provide a novel strategy for the treatment of IVDD. However, there are no reports about the clinical applications of small molecules targeting IGF signaling on IVDD at present. The side effects produced by excessive activation or deactivation of IGF signaling may be main obstacles or peoblems in the clinical management. Research on the dose, frequency, and safety of IGF injection is still lacking. A followup issue that needs to be addressed in the future is to determine the ideal timing of the interventions. In a word, the application of IGF for IVD regeneration appears promising. Nevertheless, further basic research is still needed before clinical use (Kennon et al., 2018).

\section{CONCLUSION}

IVDD is the leading contributor to LBP which causes great economic loss and disability globally. Emerging evidence has highlighted the important roles of IGF signaling in the

\section{REFERENCES}

Akyuva, Y., Kaplan, N., Yilmaz, I., Ozbek, H., Sirin, D. Y., Karaaslan, N., et al. (2019). Delivering Growth Factors through a Polymeric Scaffold to Cell Cultures Containing Both Nucleus Pulposus and Annulus Fibrosus. Turk Neurosurg. 29, 180-193. doi:10.5137/1019-5149.JTN.22672-18.1

Bergknut, N., Smolders, L. A., Grinwis, G. C. M., Hagman, R., Lagerstedt, A.-S., Hazewinkel, H. A. W., et al. (2013). Intervertebral Disc Degeneration in the Dog. Part 1: Anatomy and Physiology of the Intervertebral Disc and Characteristics of Intervertebral Disc Degeneration. Vet. J. 195, 282-291. doi:10.1016/j.tvjl.2012.10.024

Bikle, D. D., Tahimic, C., Chang, W., Wang, Y., Philippou, A., and Barton, E. R. (2015). Role of IGF-I Signaling in Muscle Bone Interactions. Bone 80, 79-88. doi:10.1016/j.bone.2015.04.036 pathogenesis of IVDD. However, the precise mechanisms remain unclear. The activation of IGF signaling can retard IVDD by inhibiting cell apoptosis, cell senescence, matrix degradation, inflammatory and promoting cell proliferation, matrix synthesis. Unfortunately, the abnormal activation of IGF signaling can accelerate IVDD by stimulating excessive cell proliferation, increasing vascular and nerve growth, aggravating nutritional deficiency (Figure 3). Thus there are still a variety of challenges to address when we perform IGFcentered therapy for IVDD. In addition, there is still no ideal way to make drugs reach the intervertebral discs safely and effectively and the studies performed in patients are still lacking. It is urgent to elaborate on the application of IGF signaling in clinical trials to optimize the IGF-based therapy for IVDD treatment.

\section{AUTHOR CONTRIBUTIONS}

S-ZW and Q-XC performed the conception and design of this study. $\mathrm{LH}, \quad \mathrm{TS}$ and P-YZ conducted the literature search and summarization. $\mathrm{LH}, \mathrm{WL}$ and $\mathrm{XY}$ rafted the manuscript and reorganized and edited the draft. S-ZW and $\mathrm{XY}$ revised the manuscript. S-ZW and Q-XC gave final approval of the version to be submitted. LH, TS and P-YZ contributed equally to this study. All authors have read and approved the final manuscript.

\section{FUNDING}

This study was supported by grant 2016YFC1100100 from The National Key Research and Development Program of China and a grant from the Major Research Plan of the National Natural Science Foundation of China (grant number 91649204) and grant 2020xhyn007 from Science Foundation of Union Hospital.

\section{SUPPLEMENTARY MATERIAL}

The Supplementary Material for this article can be found online at: https://www.frontiersin.org/articles/10.3389/fcell.2021.817099/ full\#supplementary-material

Buckwalter, J. A. (1995). Aging and Degeneration of the Human Intervertebral Disc. Spine 20, 1307-1314. doi:10.1097/00007632-199506000-00022

Chao, C.-C., Lee, W.-F., Yang, W.-H., Lin, C.-Y., Han, C.-K., Huang, Y.-L., et al. (2021). IGFBP-3 Stimulates Human Osteosarcoma Cell Migration by Upregulating VCAM-1 Expression. Life Sci. 265, 118758. doi:10.1016/ j.lfs.2020.118758

Chen, R. S., Zhang, X. B., Zhu, X. T., and Wang, C. S. (2020). The Crosstalk between IGF-1R and ER- $\alpha$ in the Proliferation and Anti-Inflammation of Nucleus Pulposus Cells. Eur. Rev. Med. Pharmacol. Sci. 24, 5886-5894. doi:10.26355/ eurrev_202006_21481

Chen, S., Lv, X., Hu, B., Shao, Z., Wang, B., Ma, K., et al. (2017). RIPK1/RIPK3/ MLKL-Mediated Necroptosis Contributes to Compression-Induced Rat Nucleus Pulposus Cells Death. Apoptosis 22, 626-638. doi:10.1007/s10495017-1358-2 
Chen, Y.-C., Su, W.-Y., Yang, S.-H., Gefen, A., and Lin, F.-H. (2013). In Situ forming Hydrogels Composed of Oxidized High Molecular Weight Hyaluronic Acid and Gelatin for Nucleus Pulposus Regeneration. Acta Biomater. 9, 5181-5193. doi:10.1016/j.actbio.2012.09.039

Choi, M. C., Jo, J., Park, J., Kang, H. K., and Park, Y. (2019). NF-кB Signaling Pathways in Osteoarthritic Cartilage Destruction. Cells 8, 734. doi:10.3390/ cells 8070734

Chon, B. H., Lee, E. J., Jing, L., Setton, L. A., and Chen, J. (2013). Human Umbilical Cord Mesenchymal Stromal Cells Exhibit Immature Nucleus Pulposus Cell Phenotype in a Laminin-Rich Pseudo-Three-Dimensional Culture System. Stem Cel Res Ther 4, 120. doi:10.1186/scrt331

Chothe, P. P., Chutkan, N., Sangani, R., Wenger, K. H., Prasad, P. D., Thangaraju, M., et al. (2013). Sodium-Coupled Vitamin C Transporter (SVCT2): Expression, Function, and Regulation in Intervertebral Disc Cells. Spine J. 13, 549-557. doi:10.1016/j.spinee.2013.01.022

Chou, P.-H., Wang, S.-T., Yen, M.-H., Liu, C.-L., Chang, M.-C., and Lee, O. K.-S. (2016). Fluid-Induced, Shear Stress-Regulated Extracellular Matrix and Matrix Metalloproteinase Genes Expression on Human Annulus Fibrosus Cells. Stem Cel Res Ther 7, 34. doi:10.1186/s13287-016-0292-5

Chung, S. A., Khan, S. N., and Diwan, A. D. (2003). The Molecular Basis of Intervertebral Disk Degeneration. Orthop. Clin. North America 34, 209-219. doi:10.1016/s0030-5898(03)00026-9

Clemmons, D. (2006). Involvement of Insulin-Like Growth Factor-I in the Control of Glucose Homeostasis. Curr. Opin. Pharmacol. 6, 620-625. doi:10.1016/ j.coph.2006.08.006

DePalma, M. J., Ketchum, J. M., and Saullo, T. (2011). What Is the Source of Chronic Low Back Pain and Does Age Play a Role? Pain Med. 12, 224-233. doi:10.1111/j.1526-4637.2010.01045.x

Dixit, M., Poudel, S. B., and Yakar, S. (2021). Effects of GH/IGF Axis on Bone and Cartilage. Mol. Cell Endocrinol. 519, 111052. doi:10.1016/j.mce.2020.111052

Duan, C., and Xu, Q. (2005). Roles of Insulin-Like Growth Factor (IGF) Binding Proteins in Regulating IGF Actions. Gen. Comp. Endocrinol. 142, 44-52. doi:10.1016/j.ygcen.2004.12.022

Ehlicke, F., Freimark, D., Heil, B., Dorresteijn, A., and Czermak, P. (2010). Intervertebral Disc Regeneration: Influence of Growth Factors on Differentiation of Human Mesenchymal Stem Cells (hMSC). Int. J. Artif. Organs 33, 244-252. doi:10.1177/039139881003300409

Elmasry, S., Asfour, S., de Rivero Vaccari, J. P., and Travascio, F. (2016). A Computational Model for Investigating the Effects of Changes in Bioavailability of Insulin-Like Growth Factor-1 on the Homeostasis of the Intervertebral Disc. Comput. Biol. Med. 78, 126-137. doi:10.1016/j.compbiomed.2016.09.016

Feng, C., Liu, H., Yang, Y., Huang, B., and Zhou, Y. (2015). Growth and Differentiation Factor-5 Contributes to the Structural and Functional Maintenance of the Intervertebral Disc. Cell Physiol Biochem 35, 1-16. doi:10.1159/000369670

Feng, C., Yang, M., Lan, M., Liu, C., Zhang, Y., Huang, B., et al. (2017). ROS: Crucial Intermediators in the Pathogenesis of Intervertebral Disc Degeneration. Oxid Med. Cel Longev 2017, 5601593. doi:10.1155/2017/5601593

Gan, Y., Buckels, A., Liu, Y., Zhang, Y., Paterson, A. J., Jiang, J., et al. (2014). Human GH Receptor-IGF-1 Receptor Interaction: Implications for GH Signaling. Mol. Endocrinol. 28, 1841-1854. doi:10.1210/me.2014-1174

Garcia-Touchard, A., Henry, T. D., Sangiorgi, G., Spagnoli, L. G., Mauriello, A., Conover, C., et al. (2005). Extracellular Proteases in Atherosclerosis and Restenosis. Atvb 25, 1119-1127. doi:10.1161/01.atv.0000164311.48592.da

Ghannam, M., Jumah, F., Mansour, S., Samara, A., Alkhdour, S., Alzuabi, M. A., et al. (2017). Surgical Anatomy, Radiological Features, and Molecular Biology of the Lumbar Intervertebral Discs. Clin. Anat. 30, 251-266. doi:10.1002/ca.22822

Grimberg, A., and Cohen, P. (2000). Role of Insulin-Like Growth Factors and Their Binding Proteins in Growth Control and Carcinogenesis. J. Cel. Physiol. 183, 1-9. doi:10.1002/(sici)1097-4652(200004)183:1<1:aid-jcp1>3.0.co;2-j

Gruber, H. E., Hoelscher, G. L., Ingram, J. A., Bethea, S., and Hanley, E. N. (2008). IGF-1 Rescues Human Intervertebral Annulus Cells Fromin VitrostressInduced Premature Senescence. Growth Factors 26, 220-225. doi:10.1080/ 08977190802273814

Gruber, H. E., Hoelscher, G. L., Ingram, J. A., Morton, D. S., and Hanley, E. N. (2013). Human Annulus Cells Regulate PAPP-A and IGFBP-4 Expression, and Thereby Insulin-Like Growth Factor Bioavailability, in Response to
Proinflammatory Cytokine Exposurein Vitro. Connect. Tissue Res. 54, 432-438. doi:10.3109/03008207.2013.848200

Gruber, H. E., James Norton, H., Leslie, K., and Hanley, E. N. (2001). Clinical and Demographic Prognostic Indicators for Human Disc Cell Proliferation In Vitro. Spine 26, 2323-2327. doi:10.1097/00007632-200111010-00006

Gruber, H. E., Leslie, K., Ingram, J., Hoelscher, G., Norton, H. J., and Hanley, E. N. (2004). Colony Formation and Matrix Production by Human Anulus Cells. Spine 29, E267-E274. doi:10.1097/01.brs.0000129029.10036.64

Gruber, H. E., Norton, H. J., and Hanley, E. N. (2000). Anti-Apoptotic Effects of IGF-1 and PDGF on Human Intervertebral Disc Cells In Vitro. Spine 25, 2153-2157. doi:10.1097/00007632-200009010-00002

Guan, J., Harris, P., Brimble, M., Lei, Y., Lu, J., Yang, Y., et al. (2015). The Role for IGF-1-Derived Small Neuropeptides as a Therapeutic Target for Neurological Disorders. Expert Opin. Ther. Targets 19, 785-793. doi:10.1517/ 14728222.2015.1010514

Guilak, F., Nims, R. J., Dicks, A., Wu, C.-L., and Meulenbelt, I. (2018). Osteoarthritis as a Disease of the Cartilage Pericellular Matrix. Matrix Biol. 71-72, 40-50. doi:10.1016/j.matbio.2018.05.008

Guo, Y., Tian, L., Liu, X., He, Y., Chang, S., and Shen, Y. (2019). ERRFI1 Inhibits Proliferation and Inflammation of Nucleus Pulposus and Is Negatively Regulated by miR-2355-5p in Intervertebral Disc Degeneration. Spine 44, E873-E881. doi:10.1097/brs.0000000000003011

Hamilton, D. J., Séguin, C. A., Wang, J., Pilliar, R. M., and Kandel, R. A. (2006). Formation of a Nucleus Pulposus-Cartilage Endplate Construct In Vitro. Biomaterials 27, 397-405. doi:10.1016/j.biomaterials.2005.07.007

Hayes, A. J., and Ralphs, J. R. (2011). The Response of Foetal Annulus Fibrosus Cells to Growth Factors: Modulation of Matrix Synthesis by TGF-B1 and IGF-1. Histochem. Cel Biol 136, 163-175. doi:10.1007/s00418-011-0835-x

Hua, H., Kong, Q., Yin, J., Zhang, J., and Jiang, Y. (2020). Insulin-Like Growth Factor Receptor Signaling in Tumorigenesis and Drug Resistance: A challenge for Cancer Therapy. J. Hematol. Oncol. 13, 64. doi:10.1186/s13045-020-00904-3

Huang, C.-Y., Travascio, F., and Gu, W. Y. (2012). Quantitative Analysis of Exogenous IGF-1 Administration of Intervertebral Disc through Intradiscal Injection. J. Biomech. 45, 1149-1155. doi:10.1016/j.jbiomech.2012.02.005

Huang, H. J., Angelo, L. S., Rodon, J., Sun, M., Kuenkele, K.-P., Parsons, H. A., et al. (2011a). R1507, an Anti-Insulin-Like Growth Factor-1 Receptor (IGF-1R) Antibody, and EWS/FLI-1 siRNA in Ewing's Sarcoma: Convergence at the IGF/IGFR/Akt axis. PLoS One 6, e26060. doi:10.1371/journal.pone.0026060

Huang, Y., Wang, Y., Wu, C., and Tian, W. (2019). Elevated Expression of Hypoxia-Inducible Factor-2alpha Regulated Catabolic Factors during Intervertebral Disc Degeneration. Life Sci. 232, 116565. doi:10.1016/ j.lfs.2019.116565

Huang, Z., Zheng, Z., and Yan, J. (2011b). Transgenic Expression of Human IGF1 in Intervertebral Degenerative Discs. J. Int. Med. Res. 39, 446-455. doi:10.1177/ 147323001103900212

Ianza, A., Sirico, M., Bernocchi, O., and Generali, D. (2021). Role of the IGF-1 Axis in Overcoming Resistance in Breast Cancer. Front. Cel Dev. Biol. 9, 641449. doi:10.3389/fcell.2021.641449

Illien-Jünger, S., Pattappa, G., Peroglio, M., Benneker, L. M., Stoddart, M. J., Sakai, D., et al. (2012). Homing of Mesenchymal Stem Cells in Induced Degenerative Intervertebral Discs in a Whole Organ Culture System. Spine 37, 1865-1873. doi:10.1097/brs.0b013e3182544a8a

Janssen, J. A. M. J. L. (2020). New Insights from IGF-IR Stimulating Activity Analyses: Pathological Considerations. Cells 9, 862. doi:10.3390/cells9040862

Jozefiak, A., Larska, M., Pomorska-Mol, M., and Ruszkowski, J. J. (2021). The IGF1 Signaling Pathway in Viral Infections. Viruses 13, 1488. doi:10.3390/ v13081488

Kashyap, S., Zeidler, J. D., Chini, C. C. S., and Chini, E. N. (2020). Implications of the PAPP-A-IGFBP-IGF-1 Pathway in the Pathogenesis and Treatment of Polycystic Kidney Disease. Cell Signal. 73, 109698. doi:10.1016/ j.cellsig.2020.109698

Kasprzak, A. (2021). Insulin-Like Growth Factor 1 (IGF-1) Signaling in Glucose Metabolism in Colorectal Cancer. Int. J. Mol. Sci. 22, 6434. doi:10.3390/ ijms 22126434

Kennon, J. C., Awad, M. E., Chutkan, N., DeVine, J., and Fulzele, S. (2018). Current Insights on Use of Growth Factors as Therapy for Intervertebral Disc Degeneration. Biomol. Concepts 9, 43-52. doi:10.1515/bmc-2018-0003 
Kim, J.-S., Ellman, M. B., An, H. S., van Wijnen, A. J., Borgia, J. A., and Im, H.-J. (2010). Insulin-Like Growth Factor 1 Synergizes with Bone Morphogenetic Protein 7-Mediated Anabolism in Bovine Intervertebral Disc Cells. Arthritis Rheum. 62, 3706-3715. doi:10.1002/art.27733

Kim, J. W., Jeon, N., Shin, D. E., Lee, S. Y., Kim, M., Han, D. H., et al. (2021). Regeneration in Spinal Disease: Therapeutic Role of Hypoxia-Inducible Factor1 Alpha in Regeneration of Degenerative Intervertebral Disc. Int. J. Mol. Sci. 22, 5281. doi:10.3390/ijms22105281

Kobayashi-Hattori, K., Amuzie, C. J., Flannery, B. M., and Pestka, J. J. (2011). Body Composition and Hormonal Effects Following Exposure to Mycotoxin Deoxynivalenol in the High-Fat Diet-Induced Obese Mouse. Mol. Nutr. Food Res. 55, 1070-1078. doi:10.1002/mnfr.201000640

Koerner, J. D., Markova, D. Z., Yadla, S., Mendelis, J., Hilibrand, A., Vaccaro, A. R., et al. (2014). Differential Gene Expression in Anterior and Posterior Annulus Fibrosus. Spine 39, 1917-1923. doi:10.1097/brs.0000000000000590

Kritschil, R., Zhang, Z., Lei, C., Zhong, J., Dong, Q., Lee, J., et al. (2020). Effects of Suppressing Bioavailability of Insulin-Like Growth Factor on AgeAssociated Intervertebral Disc Degeneration. JOR Spine 3, e1112. doi:10.1002/jsp2.1112

Kuo, Y.-J., Wu, L.-C., Sun, J.-S., Chen, M.-H., Sun, M.-G., and Tsuang, Y.-H. (2014). Mechanical Stress-Induced Apoptosis of Nucleus Pulposus Cells: an In Vitro and In Vivo Rat Model. J. Orthopaedic Sci. 19, 313-322. doi:10.1007/ s00776-013-0510-2

Lappalainen, A. K., Vaittinen, E., Junnila, J., and Laitinen-Vapaavuori, O. (2014). Intervertebral Disc Disease in Dachshunds Radiographically Screened for Intervertebral Disc Calcifications. Acta Vet. Scand. 56, 89. doi:10.1186/ s13028-014-0089-4

Le Maitre, C. L., Pockert, A., Buttle, D. J., Freemont, A. J., and Hoyland, J. A. (2007). Matrix Synthesis and Degradation in Human Intervertebral Disc Degeneration. Biochem. Soc. Trans. 35, 652-655. doi:10.1042/BST0350652

Le Maitre, C. L., Richardson, S. M., Baird, P., Freemont, A. J., and Hoyland, J. A. (2005). Expression of Receptors for Putative Anabolic Growth Factors in Human Intervertebral Disc: Implications for Repair and Regeneration of the Disc. J. Pathol. 207, 445-452. doi:10.1002/path.1862

Lero, M. W., and Shaw, L. M. (2021). Diversity of Insulin and IGF Signaling in Breast Cancer: Implications for Therapy. Mol. Cell Endocrinol. 527, 111213. doi:10.1016/j.mce.2021.111213

Li, B., Zheng, X.-F., Ni, B.-B., Yang, Y.-H., Jiang, S.-D., Lu, H., et al. (2013). Reduced Expression of Insulin-Like Growth Factor 1 Receptor Leads to Accelerated Intervertebral Disc Degeneration in Mice. Int. J. Immunopathol Pharmacol. 26, 337-347. doi:10.1177/039463201302600207

Li, X., Liu, X., Wang, Y., Cao, F., Chen, Z., Hu, Z., et al. (2020). Intervertebral Disc Degeneration in Mice with Type II Diabetes Induced by Leptin Receptor Deficiency. BMC Musculoskelet. Disord. 21, 77. doi:10.1186/s12891-0203091-1

Liang, W., Ye, D., Dai, L., Shen, Y., and Xu, J. (2012). Overexpression of hTERT Extends Replicative Capacity of Human Nucleus Pulposus Cells, and Protects against Serum Starvation-Induced Apoptosis and Cell Cycle Arrest. J. Cel. Biochem. 113, 2112-2121. doi:10.1002/jcb.24082

Liu, Y., Rahaman, M. N., and Bal, B. S. (2014). Modulating Notochordal Differentiation of Human Induced Pluripotent Stem Cells Using Natural Nucleus Pulposus Tissue Matrix. PLoS One 9, e100885. doi:10.1371/ journal.pone.0100885

Liu, Z., Zhou, K., Fu, W., and Zhang, H. (2015). Insulin-Like Growth Factor 1 Activates PI3k/Akt Signaling to Antagonize Lumbar Disc Degeneration. Cel Physiol Biochem 37, 225-232. doi:10.1159/000430347

Loreto, C., Musumeci, G., Castorina, A., Loreto, C., and Martinez, G. (2011). Degenerative Disc Disease of Herniated Intervertebral Discs Is Associated with Extracellular Matrix Remodeling, Vimentin-Positive Cells and Cell Death. Ann. Anat. - Anatomischer Anzeiger 193, 156-162. doi:10.1016/ j.aanat.2010.12.001

Lunn, J. S., Sakowski, S. A., McGinley, L. M., Pacut, C., Hazel, T. G., Johe, K., et al. (2015). Autocrine Production of IGF-I Increases Stem Cell-Mediated Neuroprotection. Stem Cells 33, 1480-1489. doi:10.1002/stem.1933

Mahmoud, M., Kokozidou, M., Auffarth, A., and Schulze-Tanzil, G. (2020). The Relationship between Diabetes Mellitus Type II and Intervertebral Disc Degeneration in Diabetic Rodent Models: A Systematic and Comprehensive Review. Cells 9, 2208. doi:10.3390/cells9102208
Martel-Pelletier, J., Di Battista, J. A., Lajeunesse, D., and Pelletier, J.-P. (1998). IGF/ IGFBP Axis in Cartilage and Bone in Osteoarthritis Pathogenesis. Inflamm. Res. 47, 90-100. doi:10.1007/s000110050288

Mavrogonatou, E., and Kletsas, D. (2010). Effect of Varying Osmotic Conditions on the Response of Bovine Nucleus Pulposus Cells to Growth Factors and the Activation of the ERK and Akt Pathways. J. Orthop. Res. 28, 1276-1282. doi:10.1002/jor.21140

Merceron, C., Mangiavini, L., Robling, A., Wilson, T. L., Giaccia, A. J., Shapiro, I. M., et al. (2014). Loss of HIF-1a in the Notochord Results in Cell Death and Complete Disappearance of the Nucleus Pulposus. PLoS One 9, e110768. doi:10.1371/journal.pone.0110768

Moon, S.-H., Nishida, K., Gilbertson, L. G., Lee, H.-M., Kim, H., Hall, R. A., et al. (2008). Biologic Response of Human Intervertebral Disc Cells to Gene Therapy Cocktail. Spine 33, 1850-1855. doi:10.1097/brs.0b013e31817elcd7

Moonesi, M., Zaka Khosravi, S., Molaei Ramshe, S., Allahbakhshian Farsani, M., Solali, S., Mohammadi, M. H., et al. (2021). IGF Family Effects on Development, Stability, and Treatment of Hematological Malignancies. J. Cel Physiol 236, 4097-4105. doi:10.1002/jcp.30156

Murakami, H., Yoon, S. T., Attallah-Wasif, E. S., Tsai, K.-J., Fei, Q., and Hutton, W. C. (2006). The Expression of Anabolic Cytokines in Intervertebral Discs in AgeRelated Degeneration. Spine 31, 1770-1774. doi:10.1097/ 01.brs.0000227255.39896.f3

Oichi, T., Taniguchi, Y., Oshima, Y., Tanaka, S., and Saito, T. (2020). Pathomechanism of Intervertebral Disc Degeneration. JOR Spine 3, e1076. doi:10.1002/jsp2.1076

Okamoto, N., Nakamori, R., Murai, T., Yamauchi, Y., Masuda, A., and Nishimura, T. (2013). A Secreted Decoy of InR Antagonizes Insulin/IGF Signaling to Restrict Body Growth in Drosophila. Genes Dev. 27, 87-97. doi:10.1101/gad.204479.112

Okuda, S. y., Myoui, A., Ariga, K., Nakase, T., Yonenobu, K., and Yoshikawa, H. (2001). Mechanisms of Age-Related Decline in Insulin-Like Growth Factor-I Dependent Proteoglycan Synthesis in Rat Intervertebral Disc Cells. Spine 26, 2421-2426. doi:10.1097/00007632-200111150-00005

Osada, R., Ohshima, H., Ishihara, H., Yudoh, K., Sakai, K., Matsui, H., et al. (1996). Autocrine/Paracrine Mechanism of Insulin-Like Growth Factor-1 Secretion, and the Effect of Insulin-Like Growth Factor-1 on Proteoglycan Synthesis in Bovine Intervertebral Discs. J. Orthop. Res. 14, 690-699. doi:10.1002/jor.1100140503

Osher, E., and Macaulay, V. M. (2019). Therapeutic Targeting of the IGF Axis. Cells 8, 895. doi: $10.3390 /$ cells 8080895

Patel, B. B., and Majumdar, A. P. N. (2009). Synergistic Role of Curcumin with Current Therapeutics in Colorectal Cancer: Minireview. Nutr. Cancer 61, 842-846. doi:10.1080/01635580903285106

Pattison, S., Melrose, J., Ghosh, P., and Taylor, T. K. (2001). Regulation Of Gelatinase-A (MMP-2) Production By Ovine Intervertebral Disc Nucleus Pulposus Cells Grown In Alginate Bead Culture By Transforming Growth Factor-Bland Insulin Like Growth Factor-I. Cel Biol. Int. 25, 679-689. doi:10.1006/cbir.2000.0718

Peters, G., Gongoll, S., Langner, C., Mengel, M., Piso, P., Klempnauer, J., et al. (2003). IGF-1R, IGF-1 and IGF-2 Expression as Potential Prognostic and Predictive Markers in Colorectal-Cancer. Virchows Arch. 443, 139-145. doi:10.1007/s00428-003-0856-5

Pockert, A. J., Richardson, S. M., Le Maitre, C. L., Lyon, M., Deakin, J. A., Buttle, D. J., et al. (2009). Modified Expression of the ADAMTS Enzymes and Tissue Inhibitor of Metalloproteinases 3 during Human Intervertebral Disc Degeneration. Arthritis Rheum. 60, 482-491. doi:10.1002/art.24291

Pratsinis, H., Constantinou, V., Pavlakis, K., Sapkas, G., and Kletsas, D. (2012). Exogenous and Autocrine Growth Factors Stimulate Human Intervertebral Disc Cell Proliferation via the ERK and Akt Pathways. J. Orthop. Res. 30, 958-964. doi:10.1002/jor.22017

Pratsinis, H., and Kletsas, D. (2007). PDGF, bFGF and IGF-I Stimulate the Proliferation of Intervertebral Disc Cells In Vitro via the Activation of the ERK and Akt Signaling Pathways. Eur. Spine J. 16, 1858-1866. doi:10.1007/s00586-007-0408-9

Price, V., Wells, P., Tucci, M., Cameron, J. A., Ragab, A., and Benghuzzi, H. (2007). Effects of Sustained Delivery of IGF-1 in a Rat Degenerative Disc Model. Biomed. Sci. Instrum 43, 384-389.

Rafacho, A., Giozzet, V. A. G., Boschero, A. C., Abrantes, J. L. F., Cestari, T. M., Carneiro, E. M., et al. (2009). Reduced Pancreatic $\beta$-Cell Mass Is Associated with Decreased FoxO1 and Erk1/2 Protein Phosphorylation in Low-Protein Malnourished Rats. Braz. J. Med. Biol. Res. 42, 935-941. doi:10.1590/s0100-879x2009001000010 
Rosenzweig, S. A. (2004). What's New in the IGF-Binding Proteins? Growth Horm. IGF Res. 14, 329-336. doi:10.1016/j.ghir.2004.02.003

Shim, E.-K., Lee, J.-S., Kim, D.-E., Kim, S. K., Jung, B.-J., Choi, E.-Y., et al. (2016). Autogenous Mesenchymal Stem Cells from the Vertebral Body Enhance Intervertebral Disc Regeneration via Paracrine Interaction: An In Vitro Pilot Study. Cel Transpl. 25, 1819-1832. doi:10.3727/096368916x691420

Silagi, E. S., Shapiro, I. M., and Risbud, M. V. (2018). Glycosaminoglycan Synthesis in the Nucleus Pulposus: Dysregulation and the Pathogenesis of Disc Degeneration. Matrix Biol. 71-72, 368-379. doi:10.1016/j.matbio.2018.02.025

Singh, R. K., Gaikwad, S. M., Jinager, A., Chaudhury, S., Maheshwari, A., and Ray, P. (2014). IGF-1R Inhibition Potentiates Cytotoxic Effects of Chemotherapeutic Agents in Early Stages of Chemoresistant Ovarian Cancer Cells. Cancer Lett. 354, 254-262. doi:10.1016/j.canlet.2014.08.023

Sivan, S. S., Wachtel, E., and Roughley, P. (2014). Structure, Function, Aging and Turnover of Aggrecan in the Intervertebral Disc. Biochimica et Biophysica Acta (BBA)-General Subjects 1840 (10), 3181-3189. doi:10.1016/j.bbagen.2014.07.013

Specchia, N., Pagnotta, A., Toesca, A., and Greco, F. (2002). Cytokines and Growth Factors in the Protruded Intervertebral Disc of the Lumbar Spine. Eur. Spine J. 11, 145-151. doi:10.1007/s00586-001-0361-y

Takayama, B., Sekiguchi, M., Yabuki, S., Kikuchi, S.-i., and Konno, S.-I. (2011). Localization and Function of Insulin-Like Growth Factor 1 in Dorsal Root Ganglia in a Rat Disc Herniation Model. Spine 36, E75-E79. doi:10.1097/ brs.0b013e3181d56208

Tao, Y., Zhou, X., Liang, C., Li, H., Han, B., Li, F., et al. (2015). TGF- $\beta 3$ and IGF-1 Synergy Ameliorates Nucleus Pulposus Mesenchymal Stem Cell Differentiation towards the Nucleus Pulposus Cell Type through MAPK/ERK Signaling. Growth Factors 33, 326-336. doi:10.3109/08977194.2015.1088532

Tian, D., Liu, J., Chen, L., Zhu, B., and Jing, J. (2020). The Protective Effects of PI3K/Akt Pathway on Human Nucleus Pulposus Mesenchymal Stem Cells against Hypoxia and Nutrition Deficiency. J. Orthop. Surg. Res. 15, 29. doi:10.1186/s13018-020-1551-9

Travascio, F., Elmasry, S., and Asfour, S. (2014). Modeling the Role of IGF-1 on Extracellular Matrix Biosynthesis and Cellularity in Intervertebral Disc. J. Biomech. 47, 2269-2276. doi:10.1016/j.jbiomech.2014.04.046

Tsarouhas, A., Soufla, G., Katonis, P., Pasku, D., Vakis, A., and Spandidos, D. A. (2011). Transcript Levels of Major MMPs and ADAMTS-4 in Relation to the Clinicopathological Profile of Patients with Lumbar Disc Herniation. Eur. Spine J. 20, 781-790. doi:10.1007/s00586-010-1573-9

Tsarouhas, A., Soufla, G., Tsarouhas, K., Katonis, P., Pasku, D., Vakis, A., et al. (2017). Molecular Profile of Major Growth Factors in Lumbar Intervertebral Disc Herniation: Correlation with Patient Clinical and Epidemiological Characteristics. Mol. Med. Rep. 15, 2195-2203. doi:10.3892/mmr.2017.6221

Urban, J. P. G., Smith, S., and Fairbank, J. C. T. (2004). Nutrition of the Intervertebral Disc. Spine 29, 2700-2709. doi:10.1097/01.brs.0000146499.97948.52

Vadalà, G., Russo, F., Di Martino, A., and Denaro, V. (2015). Intervertebral Disc Regeneration: From the Degenerative cascade to Molecular Therapy and Tissue Engineering. J. Tissue Eng. Regen. Med. 9, 679-690. doi:10.1002/term.1719

Wang, Q., Liu, L., Li, H., McCullough, L. E., Qi, Y.-n., Li, J.-y., et al. (2014). Genetic and Dietary Determinants of Insulin-Like Growth Factor (IGF)-1 and IGF Binding Protein (BP)-3 Levels Among Chinese Women. PLoS One 9, e108934. doi:10.1371/journal.pone.0108934

Wang, W.-J., Yu, X.-H., Wang, C., Yang, W., He, W.-S., Zhang, S.-J., et al. (2015a). MMPs and ADAMTSs in Intervertebral Disc Degeneration. Clinica Chim. Acta 448, 238-246. doi:10.1016/j.cca.2015.06.023

Wang, Y., Che, M., Xin, J., Zheng, Z., Li, J., and Zhang, S. (2020). The Role of IL-1 $\beta$ and TNF- $\alpha$ in Intervertebral Disc Degeneration. Biomed. Pharmacother. 131, 110660. doi:10.1016/j.biopha.2020.110660

Wang, Y., Nishida, S., Sakata, T., Elalieh, H. Z., Chang, W., Halloran, B. P., et al. (2006). Insulin-Like Growth Factor-I Is Essential for Embryonic Bone Development. Endocrinology 147, 4753-4761. doi:10.1210/en.2006-0196

Wang, Z., Wang, G., Zhu, X., Geng, D., and Yang, H. (2015b). Interleukin-2 Is Upregulated in Patients with a Prolapsed Lumbar Intervertebral Disc and
Modulates Cell Proliferation, Apoptosis and Extracellular Matrix Metabolism of Human Nucleus Pulposus Cells. Exp. Ther. Med. 10, 2437-2443. doi:10.3892/ etm.2015.2809

Wei, Y., Zhi-Hong, W., Gui-Xing, Q., Bin, Y., Jun, C., and Yi-Peng, W. (2013). Extracellular Signal-Regulated Kinase Inhibition Modulates Rat Annulus Fibrosus Cell Response to Interleukin-1. Spine 38, E1075-E1081. doi:10.1097/brs.0b013e31829a6930

Wong, J., Sampson, S. L., Bell-Briones, H., Ouyang, A., Lazar, A. A., Lotz, J. C., et al. (2019). Nutrient Supply and Nucleus Pulposus Cell Function: Effects of the Transport Properties of the Cartilage Endplate and Potential Implications for Intradiscal Biologic Therapy. Osteoarthritis and Cartilage 27, 956-964. doi:10.1016/j.joca.2019.01.013

Xu, Z., Zhou, X., and Chen, G. (2019). Expression and Mechanism of Interleukin 1 (IL-1), Interleukin 2 (IL-2), Interleukin 8 (IL-8), BMP, Fibroblast Growth Factor 1 (FGF1), and Insulin-like Growth Factor (IGF-1) in Lumbar Disc Herniation. Med. Sci. Monit. 25, 984-990. doi:10.12659/msm.911910

Yoshida, T., and Delafontaine, P. (2020). Mechanisms of IGF-1-Mediated Regulation of Skeletal Muscle Hypertrophy and Atrophy. Cells 9, 1970. doi:10.3390/cells9091970

Zhang, C.-C., Cui, G.-P., Hu, J.-G., Xiao, Y.-Z., Zhou, X.-S., Shao, C., et al. (2014). Effects of Adenoviral Vector Expressing hIGF-1 on Apoptosis in Nucleus Pulposus Cells In Vitro. Int. J. Mol. Med. 33, 401-405. doi:10.3892/ ijmm.2013.1586

Zhang, C.-C., Zhou, J.-S., Hu, J.-G., Wang, X., Zhou, X.-S., Sun, B.-A., et al. (2013). Effects of IGF-1 on IL-1 $\beta$-Induced Apoptosis in Rabbit Nucleus Pulposus Cells In Vitro. Mol. Med. Rep. 7, 441-444. doi:10.3892/mmr.2012.1238

Zhang, G. Z., Liu, M. Q., Chen, H. W., Wu, Z. L., Gao, Y. C., Ma, Z. J., et al. (2021). NF-кB Signalling Pathways in Nucleus Pulposus Cell Function and Intervertebral Disc Degeneration. Cell Prolif 54, e13057. doi:10.1111/cpr.13057

Zhang, M., Zhou, Q., Liang, Q.-Q., Li, C.-G., Holz, J. D., Tang, D., et al. (2009). IGF1 Regulation of Type II Collagen and MMP-13 Expression in Rat Endplate Chondrocytes via Distinct Signaling Pathways. Osteoarthritis and Cartilage 17, 100-106. doi:10.1016/j.joca.2008.05.007

Zhang, R., Ruan, D., and Zhang, C. (2006). Effects of TGF-B1 and IGF-1 on Proliferation of Human Nucleus Pulposus Cells in Medium with Different Serum Concentrations. J. Orthop. Surg. Res. 1, 9. doi:10.1186/1749-799x-1-9

Zhang, Y., He, F., Chen, Z., Su, Q., Yan, M., Zhang, Q., et al. (2019). Melatonin Modulates IL-1 $\beta$-Induced Extracellular Matrix Remodeling in Human Nucleus Pulposus Cells and Attenuates Rat Intervertebral Disc Degeneration and Inflammation. Aging 11, 10499-10512. doi:10.18632/aging.102472

Zhao, X., Shen, P., Li, H., Yang, Y., Guo, J., Chen, S., et al. (2020). Carbonic Anhydrase 12 Protects Endplate Cartilage from Degeneration Regulated by IGF-1/PI3K/CREB Signaling Pathway. Front. Cel Dev. Biol. 8, 595969. doi:10.3389/fcell.2020.595969

Conflict of Interest: The authors declare that the research was conducted in the absence of any commercial or financial relationships that could be construed as a potential conflict of interest.

Publisher's Note: All claims expressed in this article are solely those of the authors and do not necessarily represent those of their affiliated organizations, or those of the publisher, the editors and the reviewers. Any product that may be evaluated in this article, or claim that may be made by its manufacturer, is not guaranteed or endorsed by the publisher.

Copyright $\odot 2022$ Lin, Tian, Peng, Wu, Xiao, Qing and Shao. This is an open-access article distributed under the terms of the Creative Commons Attribution License (CC $B Y)$. The use, distribution or reproduction in other forums is permitted, provided the original author(s) and the copyright owner(s) are credited and that the original publication in this journal is cited, in accordance with accepted academic practice. No use, distribution or reproduction is permitted which does not comply with these terms. 